\title{
Methyl Aryloxy Gallates as Regulators of Vascular Smooth Muscle Cell Proliferation
}

\author{
Jae-Hwan Kwalk, Jin-Kyung In, Mi-Sung Lee, Ji-Yeon Yu, Yeo-Pyo Yun, Jin Tae Hong, Soo Jae Lee, Seung-Yong Seo, ${ }^{\dagger}$ \\ Soon Kil Ahn, ${ }^{\ddagger}$ Young-Ger Suh, ${ }^{\S}$ Bang-Yeon Hwang, Heesoon Lee, Kyung Hoon Min, ${ }^{\#, *}$ and Jae-Kyung Jung ${ }^{*}$

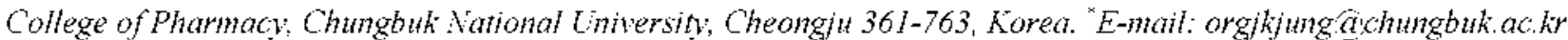 \\ ${ }^{\dagger}$ College of Pharmacy, Hoosuk Cniversity. Hanju 565-701, Korea \\ ${ }^{\ddagger}$ Equispham Co. Ltd., Gyeonggi-Do +43-766, Korea \\ College of Pharmacy, Seoul Vational Inversity, Seoul 151-742. Korea \\ "College of Phammacy Chtng-Ang Lniversity, Seoul 156-756, Korea. "E-mail Khminacatuackr \\ Received November 6. 2009. Accepted November 13. 2009
}

Key Words: Atherosclerosis. Vascular smooth muscle cell. Obovatol. Methỵl gallate, PDGF

Abnormal proliferation and migration of vascular smooth muscle cell (VSMC) have been shown to be important events in pathogenesis of atherosclerosis. Platelet-derived growth factor (PDGF) plays a key role in the VSMC proliferation and phenotypic transform among many factors contributing to VSMC activation. ${ }^{1}$ Among PDGF family (PDGF-AA, AB, BB, CC. DD) PDGF-BB can bind to all PDGF receptors with high affinity and strongly stimulates VSMC proliferation. Thus. regulation of PDGF-BB-induced VSMC proliferation is considered to be a promising therapeutic target to prevent progression of atherosclerosis.

With respect to the development of small molecule regulator with antiproliferative effect on VSMC. we have reported that

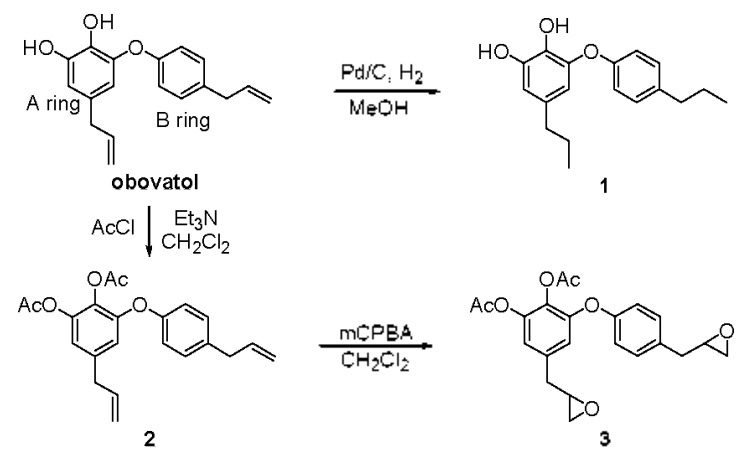

Scheme 1. Obovatol and synthesis of its derivatives<smiles>COC(=O)c1cc(O)c(O)c(O)c1</smiles>

Methyl gallate

$\underset{\substack{\mathrm{DMF} \\ \mathrm{TESCl} \mathrm{K}_{2} \mathrm{CO}_{3}}}{\mathrm{~T}}$<smiles>COCCOc1cc(C(=O)OC)cc(O)c1O</smiles>
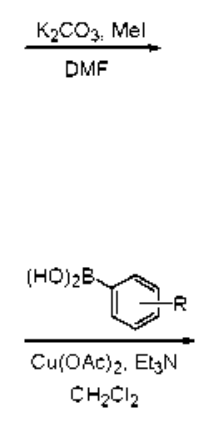<smiles>COC(=O)c1cc(O)c(OC)c(OC)c1</smiles>

4

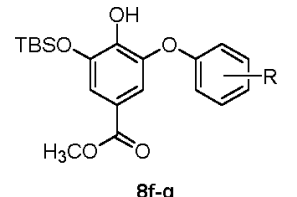

8f-g obovatol, isolated from Magnolia oborata. potently inhibit the growth of rat aortic VSMCs and DNA synthesis induced by platelet-derived growth factor (PDGF)-BB. ${ }^{2}$ Based on our previous results, combined with our continuing efforts toward diaryl ether compounds. ${ }^{3}$ we have made efforts to develop more potent molecules through studies on structure activity relationship. Herein we report synthesis of obovatol derivatives and their anti-proliferative effects on rat aortic VSMC. a cellular model for SMC proliferation.

The synthetic route for the obovatol derivatives is illustrated in Scheme 1 and 2. Most compounds were obtained according to the procedure in our previous report. ${ }^{4}$ In brief. with methyl gallate in hand, selective dimethylation and $\mathrm{Cu}(\mathrm{OAc})_{2}$ catalyzed etherification provided the desired diaryl ethers. Cleavage of methyl ethers with $\mathrm{BBr}_{3}$ furnished catechol derivatives. Synthesis of derivatives bearing alkoxy group in B ring was accomplished ria mono TBS-protected intermediate. which was obtained by reacting metlyl gallate with TBSCl only under $\mathrm{K}_{2} \mathrm{CO}_{3}$ in DMF. Other conditions using tert-anine such as $\mathrm{Et}_{3} \mathrm{~N}$ and Hünig base gave the product in a poor yield due to many undesired side reactions.

Rat aortic vascular smooth muscle cells (RAVSMCs) were isolated by enzymatic dispersion according to the modified method of Chamley et $a t^{2,5}$

The anti-proliferation activity of the obovatol derivatives at $10 \mu \mathrm{M}$ is summarized in Table 1 . Saturated obovatol analog 1 was equipotent to obovatol. Acetylated analog 2 of obovatol

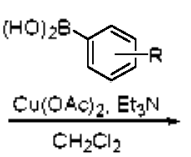

TBAF
Scheme 2. Synthesis of derivatives from methyl gallate 
Table 1. Anti-proliferation activity of obovatol derivatives at $10 \mu \mathrm{M}$

\begin{tabular}{cccccccccccc}
\hline compound & obos atol & $\mathbf{1}$ & $\mathbf{2}$ & $\mathbf{3}$ & $\mathbf{5 l}$ & $\mathbf{5 e}$ & $\mathbf{5 i}$ & $\mathbf{5 h}$ & $\mathbf{5 c}$ & $\mathbf{5 k}$ & $\mathbf{6 a}$ \\
\hline \%inhibition & 100 & 100 & 100 & 0 & 0 & 12.3 & 100 & 0 & 0 & 0 & $\mathbf{l} 00$ \\
\hline \hline compound & $\mathbf{6 b}$ & $\mathbf{6 c}$ & $\mathbf{6 d}$ & $\mathbf{6 f}$ & $\mathbf{6 g}$ & $\mathbf{6 h}$ & $\mathbf{6 i}$ & $\mathbf{6 j}$ & $\mathbf{6 k}$ & $\mathbf{8 f}$ & $\mathbf{8 g}$ \\
\hline \%inhibition & 100 & 100 & 0 & 0 & 0 & 8.5 & 5.5 & 100 & 22.3 & 9.8 & 100 \\
\hline
\end{tabular}

Table 2. IC $(1)$ values of selected derivatives

\begin{tabular}{cccccccccc}
\hline compound & $\mathbf{1}$ & $\mathbf{2}$ & $\mathbf{5 i}$ & $\mathbf{6 a}$ & $\mathbf{6 b}$ & $\mathbf{6 c}$ & $\mathbf{6 j}$ & $\mathbf{8 g}$ & obovatol \\
\hline $\mathbf{I C}_{50}(\boldsymbol{\mu M})$ & 2.73 & 2.93 & 2.99 & 0.99 & 0.96 & 1.23 & 4.91 & 2.48 & 3.00 \\
\hline
\end{tabular}
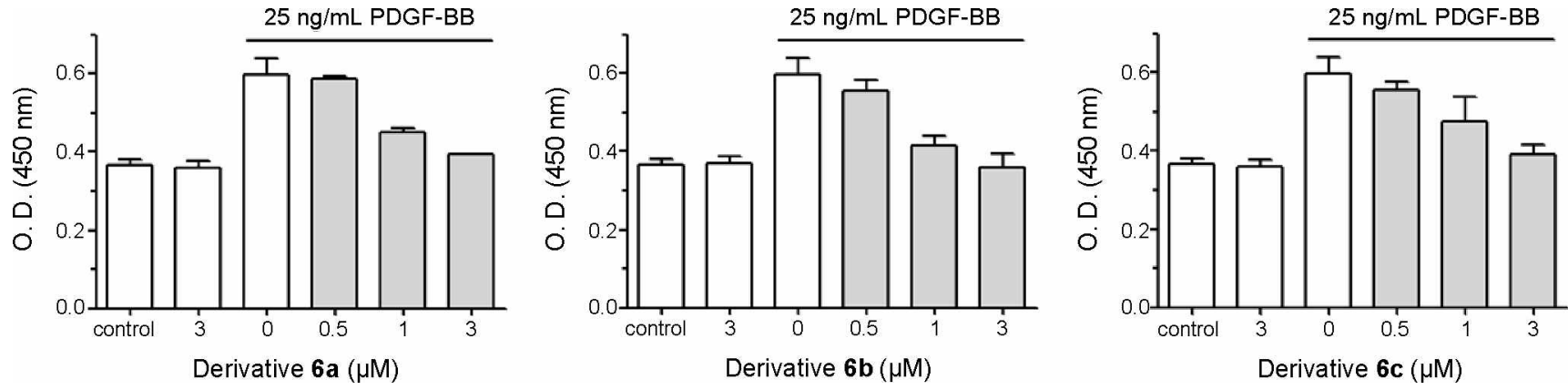

Figure 1. Effect of the representative compounds $(6 \mathrm{a}, 6 \mathrm{~b}$ and $6 \mathrm{c})$ on PDGF-BB induced proliferation in RAVSMC.

still retained anti-proliferation activity. However, introduction of oxiranes (3) led to a complete loss of activity. Methyl ester functionality was introduced to replace the ally group in A ring. These analogues were found to possess significant anti-proliferative activity for VSMC. Compound $6 \mathbf{b}$, methyl ester derivative of compound 1. was 3 -fold more active than obovatol (Table 2). We next explored modification of phenosy moiety. B ring. Incorporation of acetyl group (6k) or chloro (6i) or fluoro (6h) atom into B ring resulted in a considerable loss of activity. Derivatives possessing alkyl group such as n-propyl (6a). $n$ butyl (6b) or $t$-butỵl (6c) exhibited inhibitory effect about 3 -fold better than obovatol. As shown in Figure 1, anti-proliferative activity of derivatives for smooth muscle cells is clearly not driven from intrinsic cytotoxicity. but by inhibition of PDGF-BB dependent signaling events. Unlike chloro (6i) or fluoro (6h) compound having high electron negativity, bromo analog $(6 \mathrm{j})$ was exceptionally active, but weaker than obovatol. In addition, strong electron donating groups ( $\mathbf{6 d} \mathbf{6} \mathbf{6}$ and $\mathbf{6 g}$ ) led to complete loss of activity as well. It indicates that neither strong electronwithdrawing or donating substituents at $\mathrm{B}$ ring are favorable to activity. Unexpectedly while TBS-protected $8 \mathbf{f}$ showed very weak activity. $8 \mathrm{~g}$ showed anti-proliferative activity slightly better than obovatol. However. removal of TBS group of $\mathbf{8 g}$ resulted in loss of activity. Hence. it may not be true that TBS group is expected to be unstable and removed easily in physiological condition in this case. It has been reported that a TBSprotected compound showed excellent biological activity. ${ }^{6} \mathrm{Di}-$ rect comparison of catechol $6 \mathrm{c}$ and dimethoxy $5 \mathrm{c}$ revealed that catechol moiety is essential to exhibit anti-proliferative activity. Only 4-chloro analog $5 \mathrm{i}$ retained activity among dimethoxy derivatives thus we hypothesize it could have different binding mode.
In sunmary. we have discovered potent inhibitors for PDGFBB induced VSMC proliferation. Some methyl aryloxy gallate compounds showed better inhibitory activity than obovatol. We identified obovatol derivatives that are potentially promising agents for targeting the progression of atherosclerosis and need attention for further investigation.

Acknowledgments. This study was supported by the Korea Research Foundation Grant funded by the Korean Governument (MOEHRD) (The Regional Research Universities Program/ Chungbuk BIT Research-Oriented University Consortium) and by the Korea Science and Engineering Foundation (KOSEF) Grant funded by the Korea Government (MOST) (RI3-2008$001-00000-00)$

\section{References}

1. (a) Tedgui, A.; Mallat, Z. Phusiol Rev. 2006, 86,515. (b) Ross, R. Notime $1993,362,801$

2. Yu, I-Y.: Lee, I-I.: Jung, J-K.; Kim, T.-I.: Yoo, H.-S:; Yun, Y.-P: Lee, J.-C. Eur J. Pham. 2009, 624, 23.

3. (a) In, T.-K : Lee, M.-S.; Yang, T.-E.; Kwak, J.-H.; Lee,H.; Boovanahalli, S. K.: Lee, K.; Kim, S. J.: Moon, S. K.; Lee, S.; Choi, N. S.; Alt, S. K. Tung, J.-K. Bioorg. 1hed. Chent Lett. 2007, 17, 1799. (b) Seo, S.-Y:, Jung, I.-W, Jung, T.-K.: Kim, N.-T.; Chin, Y.-W.; Kim, J.; Sul1, Y.-G.J. Org. Chem. 2007, 72, 666.

4. Lee, M. S.; Yang, T. E.; Choi, E. H.; In, J. K : Lee, S. Y.; Lee, H.; Hong. J. T.; Lee, H. W.: Suh, Y. G.; Jung, J. K. Bull Korean Chem. Soc. 2007, 28, 1601

5. Chamley, T. H.: Groschel-Stewart, U.: Camptell, G. R.: Bunstock, G. Cell Tissue Res. 1977, 177, 445.

6. Ho, Y. K:; Bargagna-Mohan, P.; Wehenkel, M.; Mohan, R.; Kim, K. B. Chem. Biol. 2007, 14, 419. 